Article

\title{
Six-Coordinate Ln(III) Complexes with Various Coordination Geometries Showing Distinct Magnetic Properties
}

\author{
Mei Guo ${ }^{1,2}$ and Jinkui Tang ${ }^{1, *}$ \\ 1 State Key Laboratory of Rare Earth Resource Utilization, Changchun Institute of Applied Chemistry, \\ Chinese Academy of Sciences, Changchun 130022, China; mguo@ciac.ac.cn \\ 2 University of Chinese Academy of Sciences, Beijing 100049, China \\ * Correspondence: tang@ciac.ac.cn; Tel.: +86-431-85262878
}

Received: 29 November 2017; Accepted: 15 January 2018; Published: 18 January 2018

\begin{abstract}
The syntheses, structural characterization, and magnetic properties of three lanthanide complexes with formulas $\left[\mathrm{Ln}\left(\mathrm{L}^{1}\right)_{3}\right](\mathrm{Ln}=\mathrm{Dy}(\mathbf{1 D y}) ; \operatorname{Er}(\mathbf{1 E r}))$; and $\left[\mathrm{Dy}\left(\mathrm{L}^{2}\right)_{2}\right](\mathbf{2} \mathrm{Dy})$ were reported. Complexes 1Dy and 1Er are isostructural with the metal ion in distorted trigonal-prismatic coordination geometry, but exhibit distinct magnetic properties due to the different shapes of electron density for Dy ${ }^{\mathrm{III}}$ (oblate) and Er ${ }^{\mathrm{III}}$ (prolate) ions. Complex 1Dy shows obvious SMM behavior under a zero direct current $(\mathrm{dc})$ field with an effective energy barrier of $31.4 \mathrm{~K}$, while complex 1Er only features SMM behavior under a 400 Oe external field with an effective energy barrier of $23.96 \mathrm{~K}$. In stark contrast, complex 2Dy with the octahedral geometry only exhibits the frequency dependence of alternating current (ac) susceptibility signals without $\chi^{\prime \prime}$ peaks under a zero dc field.
\end{abstract}

Keywords: six-coordinate geometry; trigonal-prism; octahedron; single-molecule magnets

\section{Introduction}

Single-molecule magnets (SMMs), with the individual molecules acting as tiny magnets, are the most appealing candidates to develop memory devices with ultra-high density and spintronic devices [1-6]. The realization of those potential applications firstly depends on the high magnetic blocking temperature $\left(T_{\mathrm{B}}\right)$ and large effective energy barrier $\left(U_{\text {eff }}\right)$, which have attracted the interests of chemists, physicists, and theorists [7-9]. The effective energy barrier (also called the anisotropy barrier, $\Delta E$ ) is the potential barrier hampering the reversal of the magnetization. For polynuclear transition metal SMMs, such as $\mathrm{Mn}_{12}$ [10] and $\mathrm{Mn}_{4}$ [11], the anisotropy barrier can be expressed as $\Delta E=D S^{2}$ or $D\left(S^{2}-1 / 4\right)$ for integer and half-integer spins, in which $D$ is the axial zero-field splitting parameter and $S$ is the spin of ground state. The magnetic blocking temperature $\left(T_{\mathrm{B}}\right)$ can refer to the highest temperature at which the $M(H)$ hysteresis loop is observed. It is worth noting that $T_{\mathrm{B}}$ strongly depends on the field-sweep rate. Usually, a complex with a high anisotropy barrier will not have a guaranteed high blocking temperature, which may be attributed to the fast quantum tunneling of magnetizations. Up to now, the records of blocking temperature and effective energy barrier have been achieved by the complex $\left\{\left[\left(\mathrm{Cp}^{\mathrm{ttt}}\right)_{2} \mathrm{Dy}\right]\left[\mathrm{B}\left(\mathrm{C}_{6} \mathrm{~F}_{5}\right)_{4}\right]\right\}\left(\mathrm{Cp}^{\mathrm{ttt}}=1,2,4\right.$-tri(tertbutyl)cyclopentadienide) [12,13], as reported by the Layfield and Mills groups, with $T_{\mathrm{B}}=60 \mathrm{~K}$ and $U_{\text {eff }}=1837 \mathrm{~K}$, in which the value of $U_{\text {eff }}$ is higher by more than a factor of 30 than that of the $\mathrm{Mn}_{12}$ [10], the first $\mathrm{SMM}$ with $U_{\text {eff }}=61 \mathrm{~K}$. The remarkable SMM properties of $\left\{\left[\left(\mathrm{Cp}^{\mathrm{ttt}}\right)_{2} \mathrm{Dy}\right]\left[\mathrm{B}\left(\mathrm{C}_{6} \mathrm{~F}_{5}\right)_{4}\right]\right\}$ should mainly benefit from a perfectly axial crystal field realized by the bis(cyclopentadienyl) ligand, which demonstrates that the coordination environment of lanthanide ions plays a critical role in designing and modifying the SMMs, with the exception of complex $\mathrm{N}_{2}{ }^{3-}-\mathrm{Ln}_{2}[14,15]$, where strong lanthanide-radical magnetic exchange coupling hinders 
zero-field fast relaxation pathways, and the asymmetric $\mathrm{Dy}_{2}(\mathrm{ovph})_{2}[16,17]$ with the Ising exchange interaction between Dy ${ }^{I I I}$ ions, which efficiently suppresses fast QTM [18].

Considering the various coordination geometries and numbers of lanthanide complexes, choosing the particular coordination geometry is of vital importance in order to obtain better SMMs. For DyIII ions with the oblate-shaped electron density, a crystal field in which the ligand electron density is concentrated above and below the equatorial plane is desired to enhance the magnetic anisotropy [19]. Furthermore, this kind of crystal field could lead to a highly efficient dysprosium SIM (single-ion magnet), such as $D_{4 \mathrm{~d}}$ [20-22] or $D_{5 \mathrm{~h}}$ [23-25]. Moreover, the low-coordinate lanthanide complexes are superior at controlling the coordinated environment and understanding the magneto-structural relationship [26-30].

SIMs with six-coordination geometries are still rare in the previously reported Ln-based complexes, compared with other SIMs with high coordination numbers [31,32]. Recently, Gao and co-workers reported that the complex $\left[\left(\mathrm{L}^{\mathrm{CO}}\right) \mathrm{Dy}\left(\mathrm{N}^{*}\right)_{2}\right]\left(\mathrm{L}^{\mathrm{CO}} \mathrm{H}=\left\{\mathrm{N}-\left[(2-\mathrm{MeO})-\mathrm{C}_{6} \mathrm{H}_{5}\right]\right\} \mathrm{N}=\right.$ $\mathrm{C}(\mathrm{Me}) \mathrm{CH}=\mathrm{C}(\mathrm{Me}) \mathrm{N}(\mathrm{H})\left\{\mathrm{N}^{\prime}-\left[(2-\mathrm{MeO}) \mathrm{C}_{6} \mathrm{H}_{5}\right]\right\}$ and $\left.\mathrm{HN}^{*}=\mathrm{HN}\left(\mathrm{SiMe}_{3}\right)_{2}\right)$ with trigonal-prismatic coordination geometry, exhibited a high energy barrier $U_{\text {eff }}=190 \mathrm{~K}$ under a zero dc field [33]. It is crucial to note that the magnetic axis is approximately collinear to the direction of $\left[\mathrm{N}^{*}\right]^{-}-\mathrm{N}$, resulted from the strong axial-ligand field improved by the short $\mathrm{Dy}-\mathrm{N}\left(\left[\mathrm{N}^{*}\right]^{-}\right)$bond lengths of $2.296 \AA ̊$ A. However, complexes $\mathrm{Dy}\left(\mathrm{H}_{2} \mathrm{BPz}^{\mathrm{Me}}\right)_{3}\left(\mathrm{HPz}=\right.$ pyrazole) [34] and $\mathrm{Dy}\left(\mathrm{Bc}^{\mathrm{Me}}\right)_{3}\left(\left[\mathrm{Bc}^{\mathrm{Me}}\right]^{-}=\right.$ dihydrobis(methylimidazolyl)borate) [35] both exhibit only field- or dilution-induced slow relaxation of magnetization, in which cases the averaged bond distances of Dy-N and Dy-C are 2.477 and $2.577 \AA$, respectively. Those cases have demonstrated that the occurrence of SIMs' properties not only depends on the coordination geometry, but also on the strong axial-ligand field. In contrast, the six-coordinate Ln-based complexes possessing octahedral geometries show no SIM properties under a zero dc field, such as $\left\{\left(\mathrm{H}_{2} \mathrm{O}\right)\left[\mathrm{Ln}(\mathrm{NA})_{2}\right] \cdot \mathrm{H}_{2} \mathrm{O}_{n}\left(\mathrm{H}_{2} \mathrm{NA}=5\right.\right.$-hydroxynicotinic acid) [28] and $\left[\mathrm{Yb}\left(\mathrm{H}_{3} \mathrm{~L}\right)_{2}\right] \mathrm{Cl} \cdot 5 \mathrm{CH}_{3} \mathrm{OH} \cdot \mathrm{H}_{2} \mathrm{O}\left(\mathrm{H}_{3} \mathrm{~L}=\operatorname{tri}(((2\right.$-hydroxy-3-methoxybenzyl)amino)ethyl)amine) [36], which can be attributed to the fact that the cubic $O_{\mathrm{h}}$ symmetry does not have second-order uniaxial anisotropy parameter $B_{2}^{0}[37-39]$.

Herein, we report three six-coordinate lanthanide complexes, $\left[\operatorname{Ln}\left(\mathrm{L}^{1}\right)_{3}\right](\operatorname{Ln}=\mathrm{Dy}(\mathbf{1 D y}) ; \mathrm{Er}$ (1Er)); and [Dy $\left.\left(\mathrm{L}^{2}\right)_{2}\right]$ (2Dy), where $\mathrm{HL}^{1}=2-(((2,6$-diisopropylphenyl)imino)methyl)-phenol and $\mathrm{H}_{2} \mathrm{~L}^{2}=6,6^{\prime}$-(2-(dimethylamino)ethylazanediyl)bis(methylene)bis(2,4-di-tert-butylphenol) (Scheme 1). Complexes 1Ln present the distorted trigonal-prismatic coordination geometry, while complex 2Dy shows distorted octahedral coordination geometry. The ac susceptibility data reveal the SIM behavior of 1Dy under a zero dc field, but the field-induced SIM behavior of 1Er. Without exception, complex 2Dy only shows the frequency dependence of ac signals without $\chi$ " peaks under a zero dc field, as reported previously $[28,40]$. Therefore, this series of complexes sheds light on the magneto-structural correlation of six-coordinate complexes with different geometries. Importantly, complex 1Dy is the second SIM with trigonal-prismatic coordination geometry in the absence of an external field.
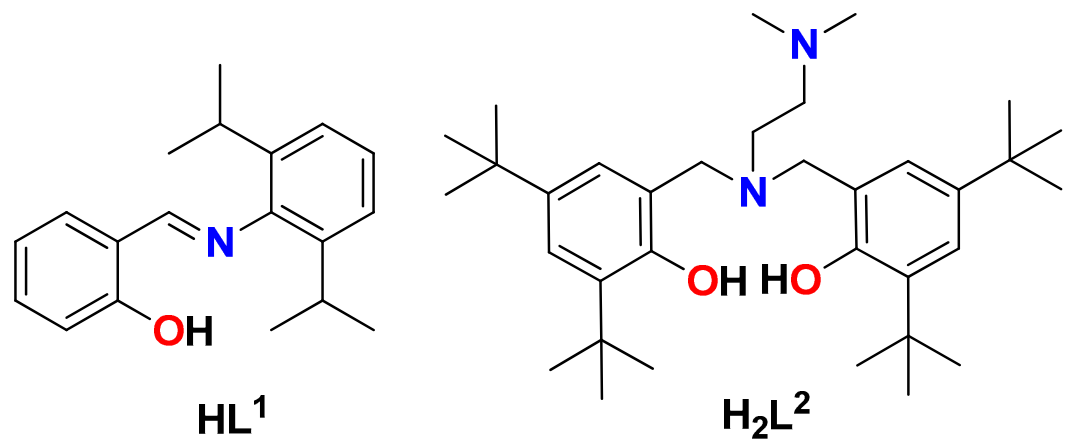

Scheme 1. The schematic diagram of ligands $\mathrm{HL}^{1}$ and $\mathrm{H}_{2} \mathrm{~L}^{2}$. 


\section{Results and Discussion}

\subsection{Crystallography}

Single-crystal X-ray diffraction investigation revealed that complexes 1Dy, 1Er (Figure 1), and 2Dy (Figure 2 ) crystallize in the triclinic $P \overline{1}$ space group with $Z=2$, in which complexes $1 \mathrm{Dy}$ and $1 \mathrm{Er}$ are isostructural. Herein, the crystal structure of 1Dy is described representatively. Details of the crystallographic data and the structure solution of three complexes are summarized in Table 1. Selected bond distances and angles are listed in Table S1 (see Supplementary Materials). The asymmetric unit of 1 Dy contains one Dy ${ }^{\mathrm{III}}$ ion with a $\left[\mathrm{N}_{3} \mathrm{O}_{3}\right]$ coordination environment, which comes from three $\left[\mathrm{L}^{1}\right]^{-}$ligands. The coordination geometry around the $\mathrm{Dy}{ }^{\mathrm{III}}$ ion is similar to the trigonal-prismatic geometry, which has been proven by the SHAPE 2.1 software [41-43], revealing that the Dy ${ }^{\mathrm{III}}$ ion is located in a distorted trigonal prism with a deviation of 2.36 from the ideal $D_{3 \mathrm{~h}}$ symmetry (Table S2, Supplementary Materials). The up and down basal planes are constructed by atoms O1, O3, and N3 and $\mathrm{O} 2, \mathrm{~N} 1$, and N2, respectively, in which the $\theta$ angle between the two planes is $13.12^{\circ}$ (Figure S1, Supplementary Materials). The bond distances of Dy-O and Dy-N are in the range of 2.144(3)-2.167(3) $\AA$ and 2.446(3)-2.606(3) $\AA$, respectively. The angles of O1-Dy-O2 and O2-Dy-O3 are $142.05^{\circ}$ and $132.32^{\circ}$, respectively. The packing arrangement along the $c$ axis (Figure S2, Supplementary Materials) demonstrates that the shortest Dy...Dy distance is $10.88 \AA$. For complex 1Er, the bond distances of Er-O and Er-N are in the range of 2.123(5)-2.146(5) $\AA$ and 2.411(4)-2.567(5) $\AA$, respectively, which are shorter than those of $1 \mathrm{Dy}$. The angles of O1-Er-O2 and O2-Er-O3 are $140.62^{\circ}$ and $132.89^{\circ}$, respectively. The $\theta$ angle between two planes is $11.56^{\circ}$ (Figure S3, Supplementary Materials), and the shortest Er $\cdots \mathrm{Er}$ distance is $10.94 \AA$ (Figure S4, Supplementary Materials).

Table 1. Crystallographic data and structure refinement details of complexes 1Dy, 1Er, and 2Dy.

\begin{tabular}{|c|c|c|c|}
\hline & 1Dy & 1Er & 2Dy \\
\hline Formula & $\mathrm{C}_{57} \mathrm{H}_{66} \mathrm{DyN}_{3} \mathrm{O}_{3}$ & $\mathrm{C}_{57} \mathrm{H}_{66} \mathrm{ErN}_{3} \mathrm{O}_{3}$ & $\mathrm{C}_{68} \mathrm{H}_{109} \mathrm{DyN}_{4} \mathrm{O}_{4}$ \\
\hline $\mathrm{FW}, \mathrm{g} \cdot \mathrm{mol}^{-1}$ & 1003.62 & 1008.38 & $1209.09^{c}$ \\
\hline crystal system & Triclinic & Triclinic & Triclinic \\
\hline space group & $P \overline{1}$ & $P \overline{1}$ & $P \overline{1}$ \\
\hline$T, K$ & 293(2) & 293(2) & $293(2)$ \\
\hline$\lambda, \AA$ & 0.71073 & 0.71073 & 0.71073 \\
\hline$a, \AA$ & $10.8822(15)$ & $10.9407(11)$ & $13.7983(12)$ \\
\hline$b, \AA$ & $11.4229(15)$ & $11.4509(11)$ & $16.6655(15)$ \\
\hline$c, \AA$ & $20.823(3)$ & $20.735(2)$ & $18.6715(17)$ \\
\hline$\alpha,{ }^{\circ}$ & $89.735(3)$ & $90.066(2)$ & $70.7220(10)$ \\
\hline$\beta, \circ$ & $88.681(3)$ & $91.458(2)$ & $77.406(2)$ \\
\hline$\gamma,{ }^{\circ}$ & $76.170(2)$ & $103.853(2)$ & $86.857(2)$ \\
\hline$V, \AA^{3}$ & $2512.7(6)$ & $2521.3(4)$ & $3954.7(6)$ \\
\hline Z & 2 & 2 & 2 \\
\hline reflns collected & 16100 & 15710 & 23959 \\
\hline unique reflns & 10012 & 9686 & 15601 \\
\hline$R_{\text {int }}$ & 0.0300 & 0.0605 & 0.0408 \\
\hline GOF on $F^{2}$ & 1.036 & 0.996 & 1.080 \\
\hline$R_{1}{ }^{\mathrm{a}}, w R_{2}{ }^{\mathrm{b}}(I \geq 2 \sigma(I))$ & $0.0381,0.0766$ & $0.0584,0.1014$ & $0.0606,0.1659$ \\
\hline$R_{1}, w R_{2}$ (all data) & $0.0476,0.0822$ & $0.0956,0.1212$ & $0.0878,0.1857$ \\
\hline CCDC number & 1586924 & 1586925 & 1586926 \\
\hline
\end{tabular}

${ }^{\mathrm{a}} R_{1}=\sum|| F_{\mathrm{o}}|-| F_{\mathrm{c}}|| / \sum\left|F_{\mathrm{o}}\right| ;{ }^{\mathrm{b}} w R_{2}=\left[\sum w\left(F_{\mathrm{o}}{ }^{2}-F_{\mathrm{c}}{ }^{2}\right)^{2} / \sum w\left(F_{\mathrm{o}}{ }^{2}\right)^{2}\right]^{1 / 2} ;{ }^{\mathrm{c}}$ The formula and the formula weight of 2Dy do not include the squeezed solvents. 


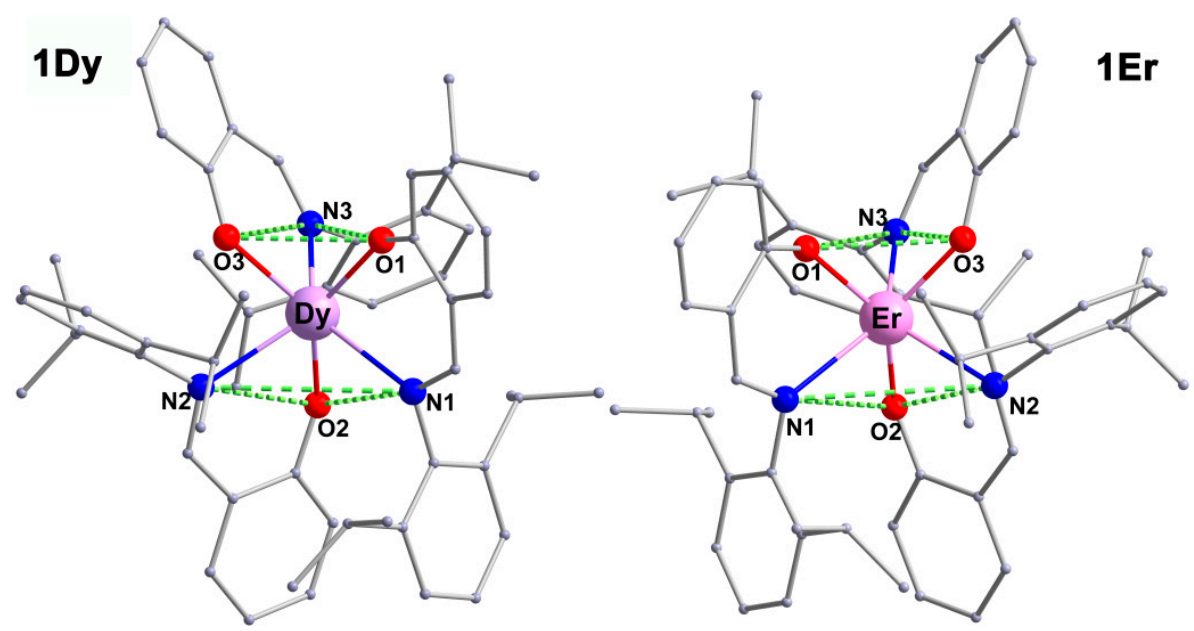

Figure 1. The molecular structures of complexes 1Dy (left) and $1 \mathrm{Er}$ (right). The dashed green lines represent the basal planes. Hydrogen atoms have been omitted for clarity.

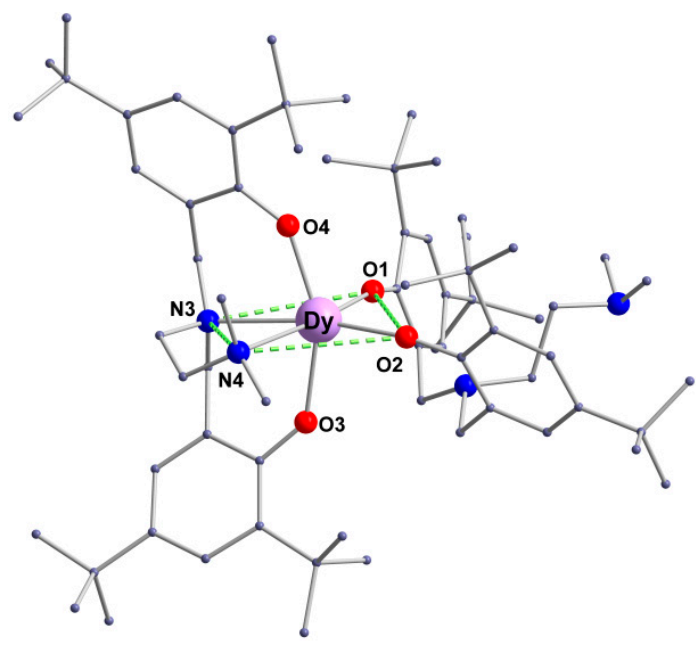

Figure 2. The molecular structure of complex 2Dy. The dashed green lines represent the equatorial plane. Hydrogen atoms have been omitted for clarity.

The Dy ${ }^{\mathrm{III}}$ ion of complex 2Dy locates in a $\left[\mathrm{N}_{4} \mathrm{O}_{2}\right]$ coordination environment, in which $\mathrm{O} 1$ and $\mathrm{O} 2$ come from one $\mathrm{H}_{2} \mathrm{~L}^{2}$ ligand, and $\mathrm{O} 3, \mathrm{O} 4, \mathrm{~N} 3$, and $\mathrm{N} 4$ come from a second $\mathrm{H}_{2} \mathrm{~L}^{2}$ ligand. The six-coordinate $\mathrm{Dy}{ }^{\mathrm{III}}$ ion is in a distorted octahedral arrangement with a deviation of 1.70 from the ideal $\mathrm{O}_{\mathrm{h}}$ symmetry (Table S2, Supplementary Materials). Two phenol $\mathrm{O}$ atoms (O3 and $\left.\mathrm{O} 4\right)$ are axially coordinated to Dy ${ }^{\mathrm{III}}$ with a Dy-O3 distance of 2.275(3) and a Dy-O4 distance of 2.170(3) $\AA$, and O3-Dy-O4 bond angle of $155.23^{\circ}$. The other bond distances of Dy-O are 2.182(3) and 2.208(3) $\AA$, which are longer than those of Dy-O4. The bond distances of Dy-N are 2.515(4) and 2.662(4) $\AA$. Furthermore, the shortest distance of the neighboring Dy ${ }^{\mathrm{III}}$ ions is $10.36 \AA$ (Figure S5, Supplementary Materials).

\subsection{Magnetic Properties}

The variable-temperature magnetic susceptibility data of complexes 1Dy, 1Er, and 2Dy were collected on the polycrystalline samples under an applied magnetic field of $1 \mathrm{kOe}$. At room temperature, the $\chi_{\mathrm{M}} T$ values (Figure 3) of $\mathbf{1 D y}, \mathbf{1 E r}$, and $\mathbf{2 D y}$ are $13.77,11.38$, and $13.21 \mathrm{~cm}^{3} \cdot \mathrm{K} \cdot \mathrm{mol}^{-1}$, respectively, which are slightly lower than the expected value for free Dy ${ }^{\mathrm{III}}\left(14.17 \mathrm{~cm}^{3} \cdot \mathrm{K} \cdot \mathrm{mol}^{-1}\right)$ and $\mathrm{Er}^{\mathrm{III}}\left(11.48 \mathrm{~cm}^{3} \cdot \mathrm{K} \cdot \mathrm{mol}^{-1}\right)$ ions. As the temperature decreased, the $\mathrm{X}_{\mathrm{M}} T$ products decrease slowly down to $2 \mathrm{~K}$, reaching values of 11.60 and $11.15 \mathrm{~cm}^{3} \cdot \mathrm{K} \cdot \mathrm{mol}^{-1}$ for $1 \mathrm{Dy}$ and $2 \mathrm{Dy}$, respectively. 
For complex 1Er, upon cooling, the $\chi_{\mathrm{M}} T$ products slightly decrease over the range of 300-100 K, followed by an obvious decrease until $2 \mathrm{~K}$ with a minimum of $7.99 \mathrm{~cm}^{3} \cdot \mathrm{K} \cdot \mathrm{mol}^{-1}$. The decrease of $\chi_{\mathrm{M}} T$ values can be attributed to the Stark level splitting of lanthanide ions with large unquenched orbital moment. The field-dependent magnetizations for complexes 1Dy and 2Dy show the same tendency (Figures S6 and S8, Supplementary Materials), as observed in most dysprosium complexes reported [44]. The magnetizations increase rapidly up to a field of $10 \mathrm{kOe}$, followed by an almost constant rise to $70 \mathrm{kOe}$, reaching values of 5.57 and $4.91 \mu_{\mathrm{B}}$ at $1.9 \mathrm{~K}$ for $1 \mathrm{Dy}$ and $2 \mathrm{Dy}$, respectively. However, a residual slope for complex 1Er (Figure S7, Supplementary Materials) is observed even at high field, and the magnetization finally reaches a value of $5.07 \mu_{\mathrm{B}}$ at $1.9 \mathrm{~K}$. The non-saturation of the field-dependent magnetizations at high field $(70 \mathrm{kOe})$ for three complexes reveal the presence of magnetic anisotropy caused by the crystal-field effects and/or low-lying excited states.

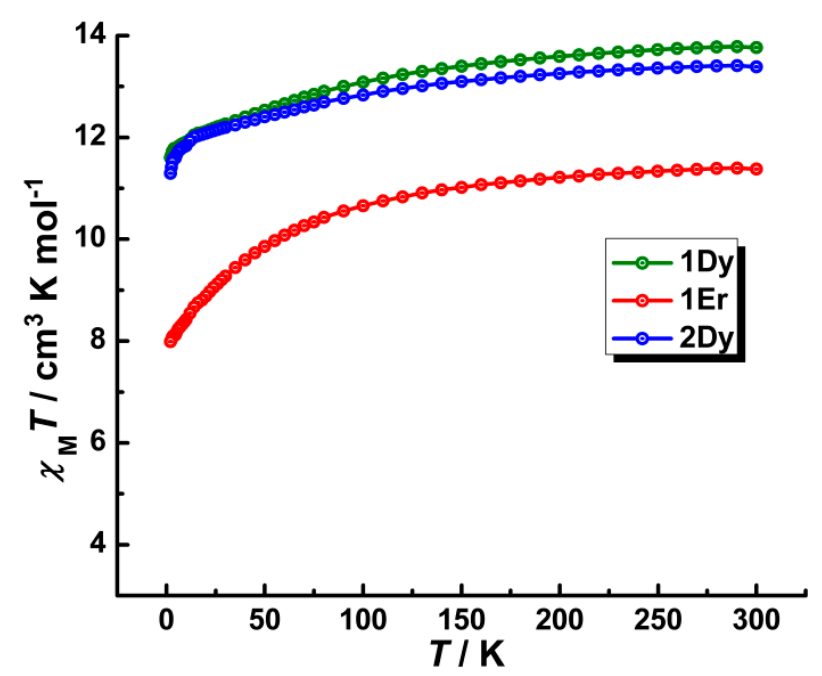

Figure 3. Plots of the $\chi_{M} T$ versus $T$ for 1Dy, 1Er and 2Dy in an applied field of $1 \mathrm{kOe}$.

Alternating current susceptibility measurements were also conducted for three complexes under zero and 400 Oe dc field to further probe the dynamics of magnetization. In the absence of an applied dc field, both in-phase $\left(\chi^{\prime}\right)$ and out-of-phase $\left(\chi^{\prime \prime}\right)$ ac susceptibilities for complex 1Dy exhibit frequency (Figure 4) and temperature (Figure S9, Supplementary Materials) dependency. However, no maximum peaks of temperature dependence of the out-of-phase $\left(\chi^{\prime \prime}\right)$ signal are observed in the range of 1-1488 Hz, which may be caused by the quantum tunneling of the magnetization (QTM), as also indicated by strong temperature-independent peaks below $9 \mathrm{~K}$ showed in Figure 4 . To evaluate the effective barrier of magnetic relaxation, the relaxation times $(\tau)$ were extracted from the plot $\chi^{\prime \prime}$ versus $v$ using the Debye model [45]. The $\tau$ versus $T^{-1}$ plot (Figure 5) shows a crossover from a linear increase of thermally activated to a temperature independent regime of QTM, which suggests the presence of more than one relaxation pathway. The plot was fitted using Equation (1), yielding effective energy barriers $U_{\text {eff }}$ of $31.40 \mathrm{~K}$ with a $\tau_{0}=3.56 \times 10^{-4} \mathrm{~s}$, where the $\tau^{-1}{ }_{\mathrm{QTM}}, A H^{2} T, C T^{n}$, and $\tau_{0}^{-1} \exp \left(-U_{\text {eff }} / k_{B} T\right)$ represent quantum tunneling, direct, Raman, and Orbach relaxation processes, respectively. For complex 1Dy, the direct process is excluded since the corresponding contribution is nullified at zero dc field. Other parameters obtained from the fitting are given in Table S3 (see Supplementary Materials).

$$
\tau^{-1}{ }_{\text {obs }}=\tau^{-1}{ }_{Q T M}+A H^{2} T+C T^{n}+\tau_{0}^{-1} \exp \left(-U_{e f f} / k_{B} T\right)
$$



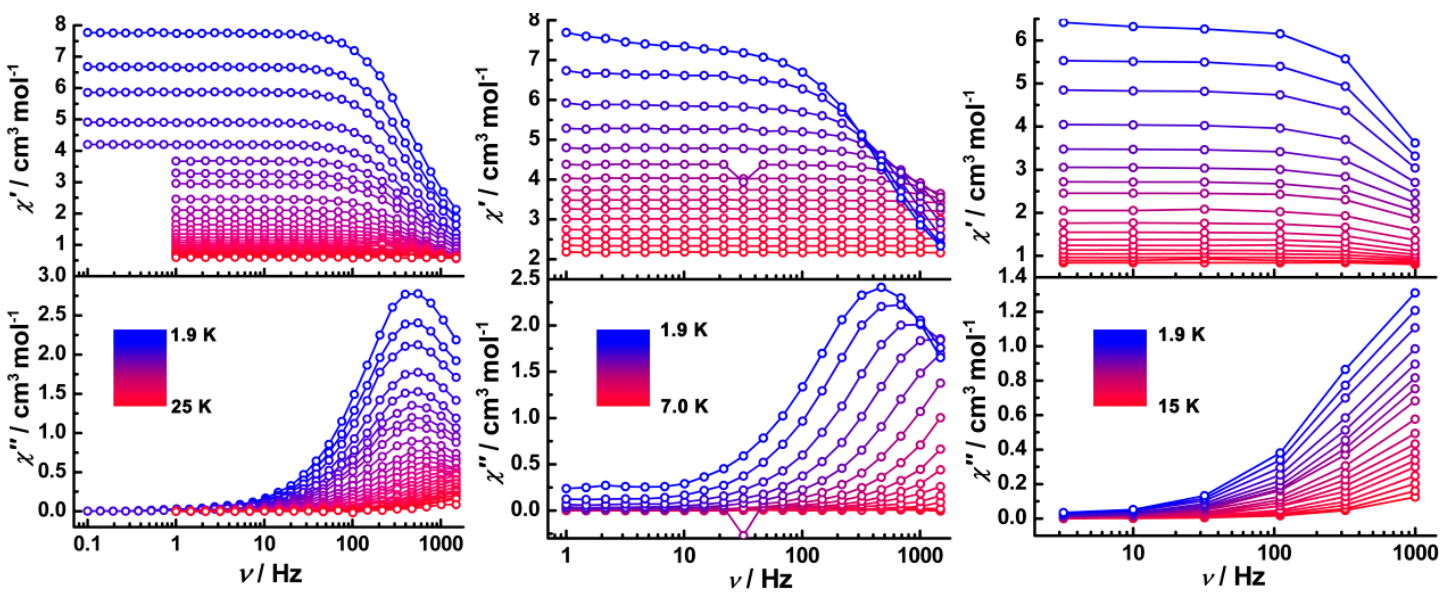

Figure 4. Frequency-dependent in-phase $\chi^{\prime}$ (top) and out-of-phase $\chi^{\prime \prime}$ (bottom) ac susceptibilities for 1Dy (left), 2Dy (right) under 0 Oe dc field, and 1Er (middle) under 400 Oe dc field.
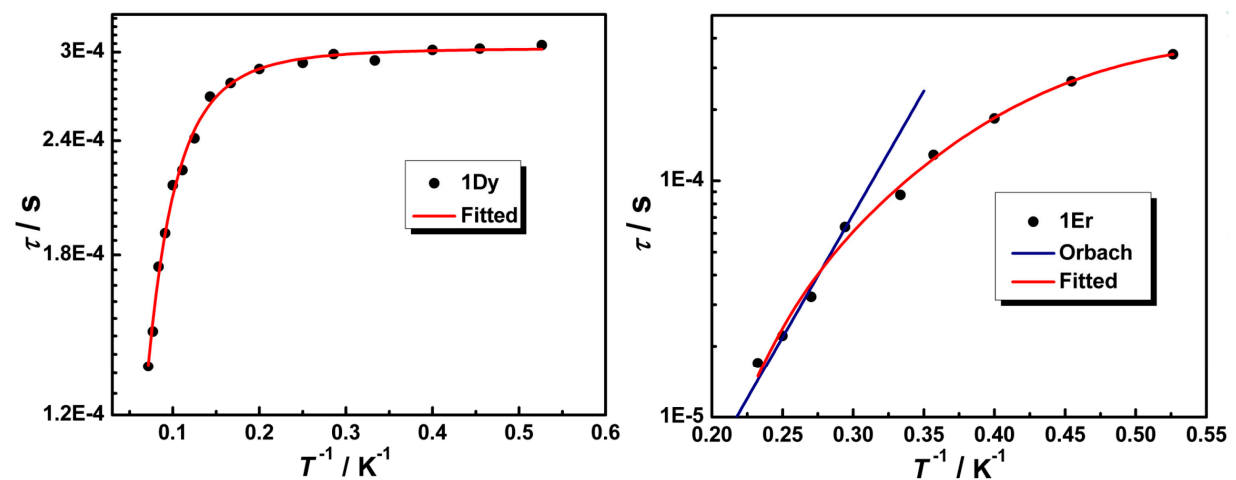

Figure 5. Plots of $\tau$ versus $T^{-1}$ for 1Dy (left) and $1 \mathrm{Er}$ (right), respectively. The red lines correspond to the best fits, and the blue line corresponds to the Orbach process.

For complex 1Er, no out-of-phase $\left(\chi^{\prime \prime}\right)$ signals (Figure S10, Supplementary Materials) were observed above $1.9 \mathrm{~K}$ at $997 \mathrm{~Hz}$, which may be attributed to the fast quantum tunneling of the magnetization at zero dc field. The rather different magnetic behaviors of 1Dy and 1Er are correlated with the axial ligand field of trigonal-prismatic coordination geometry, as Dy ${ }^{\mathrm{III}}$ is oblate and $\mathrm{Er}^{\mathrm{III}}$ is prolate [19]. In order to suppress the QTM process, the ac magnetic susceptibility measurements were also performed under a dc field (Figure S11, Supplementary Materials). The non-zero frequency- and temperature-dependent $\chi^{\prime}$ and $\chi^{\prime \prime}$ signals (Figure 4 and Figure S12, Supplementary Materials) were observed at low temperature, indicating the field-induced SMM behavior. The relaxation times $(\tau)$ of 1Er were extracted from the plot $\chi^{\prime \prime}$ versus $v$ using the Debye model. The $\tau$ versus $T^{-1}$ plot (Figure 5), showing a smooth increase as the temperature was lowered, corroborates that the QTM is suppressed to a certain extent. The plot was fitted using Equation (1), yielding effective energy barriers $U_{\text {eff }}$ of $23.96 \mathrm{~K}$ with a $\tau_{0}=5.46 \times 10^{-8} \mathrm{~s}$, and other parameters are listed in Table S3 (see Supplementary Materials). To avoid overparametrization, the direct process is canceled.

The Cole-Cole plots (Figure 6) of 1Dy and 1Er both show an asymmetrical semicircular shape, which can be fitted by the generalized Debye model [45], giving a series of $\alpha$ parameters below 0.11 from 1.9 to $13 \mathrm{~K}$ for $\mathbf{1 D y}$ and 0.13 from 1.9 to $3.7 \mathrm{~K}$ for $\mathbf{1 E r}$, respectively, which indicates a narrow distribution of the relaxation time for both complexes.

For complex 2Dy, both in-phase $\left(\chi^{\prime}\right)$ and out-of-phase $\left(\chi^{\prime \prime}\right)$ ac susceptibilities exhibited frequency (Figure 4) and temperature (Figure S13, Supplementary Materials) dependency under a zero dc field, indicative of slow relaxation of magnetization. However, no peaks of $\chi^{\prime \prime}$ were observed, indicating the presence of fast QTM relaxation. 

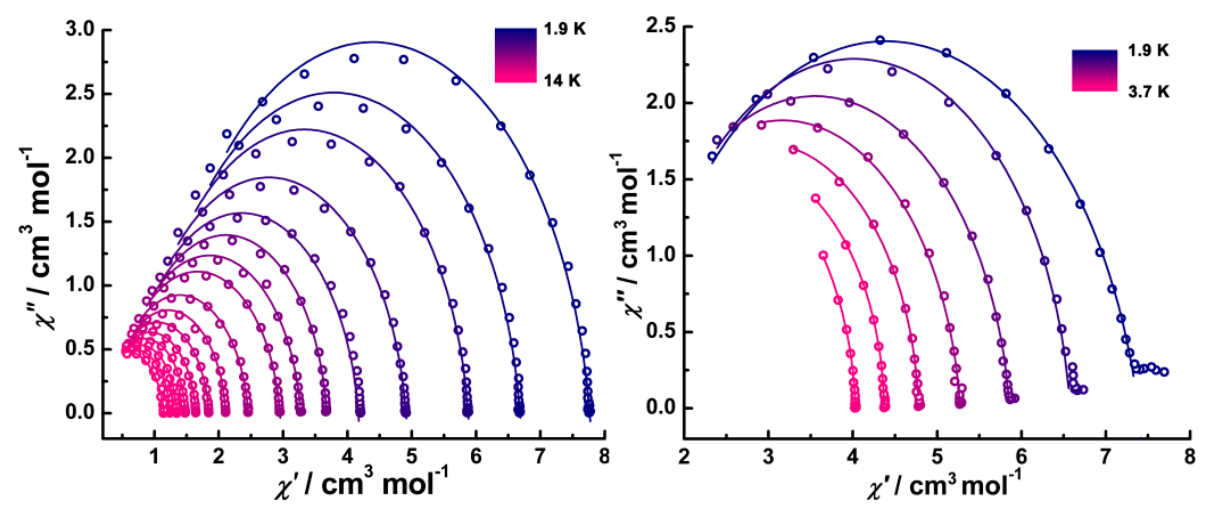

Figure 6. Cole-Cole plots for 1Dy (left) and 1Er (right) at the indicated temperature; the solid lines correspond to the best fits.

Compared with 1Ln with trigonal-prismatic geometry, the six-coordinated 2Dy with octahedral geometry demonstrates inferior magnetic properties, verifying that the coordination geometry around lanthanide ions directly affects the SMM performance. The closer the distribution of the ligands to spherical symmetry, such as the environment of cubic symmetry (octahedron, etc.), the smaller the crystal-field (CF) splitting [46]. Therefore, the trigonal prismatic geometry can improve a relatively axial ligand field compared with the octahedron, which means that the six-coordinated lanthanide-based complexes, especially dysprosium complexes, located in trigonal-prismatic geometry are more likely to show SMM behavior in principle, which coincides with our experimental results. In order to further explore the magnetic properties of these two six-coordinate Dy-based complexes, the Magellan program [47] was used to calculate the magnetic anisotropy axes of complex 1Dy (Figure 7). The results reveal that the orientation of the magnetic axis of complex 1Dy is found to be almost collinear to $\mathrm{Dy}-\mathrm{O} 2$ with an angle of $3.707^{\circ}$. Apparently, the negative charges on the $\mathrm{O}$ atoms are much larger than those on the $\mathrm{N}$ atoms for $\mathbf{1 D y}$, where it is more capable of stabilizing the ground doublet. As the ground-state wave function of complex $\left[\left(\mathrm{L}^{\mathrm{CO}}\right) \mathrm{Dy}\left(\mathrm{N}^{*}\right)_{2}\right]$ [33] featuring similar trigonal-prismatic coordination geometry around Dy ${ }^{\mathrm{III}}$ ion with complex $1 \mathrm{Dy}$ shows a dominant $M_{\mathrm{J}}= \pm 15 / 2$ doublet, the magnetic axis orientation might prefer the negative charge dense direction for the Dy ${ }^{\mathrm{III}}$ ion with the oblate shaped electron density of $\langle \pm 15 / 2>$ doublet. Herein, the calculation was based on an electrostatic model, and a further quantitative evaluation of the anisotropy axis through ab initio calculation is definitely needed.

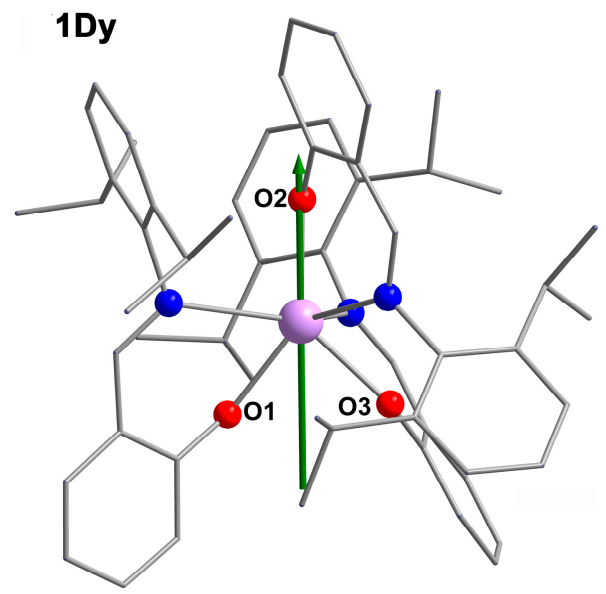

Figure 7. Ground-state magnetic anisotropy of complexes 1Dy. The green lines represent the orientations of the anisotropy axes for $\mathrm{Dy}{ }^{\mathrm{III}}$ ion (charges for the calculation: $\mathrm{Dy}+3 ; \mathrm{O}-1$; other 0 ), as calculated by the electrostatic model. 


\section{Materials and Methods}

All manipulations of air- and moisture-sensitive complexes were performed under a nitrogen atmosphere using standard Schlenk techniques and a glovebox. THF (tetrahydrofuran) and toluene were distilled under nitrogen over sodium and sodium benzophenone. Pentane and hexane were distilled under nitrogen over $\mathrm{CaH}_{2}$ (calcium hydride). $\mathrm{Ln}\left(\mathrm{N}\left(\mathrm{SiMe}_{3}\right)_{2}\right)_{3}$ [48], ligand $\mathrm{HL}^{1}$ [49], and ligand $\mathrm{H}_{2} \mathrm{~L}^{2}[50,51]$ were synthesized according to previously published procedures under ambient conditions. All other starting materials were commercially available and used without further purification. FTIR spectra were obtained using a Nicolet 6700 Flex FTIR spectrometer (Thermo Fisher Scientific, Waltham, MA, USA) equipped with smart iTR ${ }^{\mathrm{TM}}$ attenuated total reflectance (ART) sampling accessory in the range from 500 to $4000 \mathrm{~cm}^{-1}$. Elemental analysis for C, N, and $\mathrm{H}$ was carried out via a Perkin-Elmer 2400 analyzer (Perkin Elmer, Waltham, MA, USA).

X-ray crystal structure determinations. Single-crystal X-ray data of the title complexes were collected using a Bruker Apex II CCD diffractometer (Bruker, Billerica, MA, USA) equipped with graphite-monochromatized Mo K $\alpha$ radiation $(\lambda=0.71073 \AA)$. Data processing was completed using the SAINT processing program (Bruker, Billerica, MA, USA). The structures were solved by direct methods and refined by full-matrix least-squares methods on $F^{2}$ using SHELXTL-2014 [52-54]. All non-hydrogen atoms were determined from the difference Fourier maps and anisotropically refined. Hydrogen atoms were introduced at the calculated positions and refined with fixed geometry with respect to their carrier atoms. Further details may be obtained from the Cambridge Crystallographic Data Centre on quoting the depository numbers 1586924-1586926 (http:/ / www.ccdc.cam.ac.uk).

Magnetic susceptibility measurements were recorded on a Quantum Design MPMS-XL7 SQUID magnetometer (Quantum Design, San Diego, CA, USA) equipped with a $7 \mathrm{~T}$ magnet. The variable-temperature magnetization was measured in the temperature range of $1.9-300 \mathrm{~K}$ with an external magnetic field of 1000 Oe. The dynamics of the magnetization were investigated in a $3.0 \mathrm{Oe}$ ac oscillating field at different frequencies ranging from 1 to $1500 \mathrm{~Hz}$. Diamagnetic corrections for the complexes were made with the Pascal's constants [55] for all the constituent atoms as well as the contributions of the sample holder.

Synthesis of $\left[\mathrm{Dy}\left(\mathrm{L}^{1}\right)_{3}\right](1 \mathrm{Dy}) . \mathrm{Dy}\left(\mathrm{N}\left(\mathrm{SiMe}_{3}\right)_{2}\right)_{3}(0.1 \mathrm{mmol})$ in $5 \mathrm{~mL}$ of toluene was added to a solution of $\mathrm{HL}^{1}(0.3 \mathrm{mmol})$ in $10 \mathrm{~mL}$ toluene at room temperature. The solution was stirred at room temperature for $6 \mathrm{~h}$, and then filtered. After removal of toluene under reduced pressure, recrystallization of the residue in hexane at ambient temperature gave 1Dy as yellow crystals after several days. Yield: 70\%. Selected IR ( $\left.\mathrm{cm}^{-1}\right): 2960$ (s), $2926(\mathrm{~m}), 1603(\mathrm{~s}), 1583(\mathrm{~s}), 1536(\mathrm{~s}), 1464(\mathrm{~m})$, $1443(\mathrm{~s}), 1381(\mathrm{~m}), 1359(\mathrm{w}), 1254(\mathrm{w}), 1200(\mathrm{w}), 1167(\mathrm{~m}), 1143(\mathrm{~m}), 1106(\mathrm{w}), 921(\mathrm{~m}), 851(\mathrm{~m}), 792(\mathrm{~m})$, $750(\mathrm{~m}), 739(\mathrm{~m}), 593(\mathrm{w})$. Anal. Calcd. for $\left[\mathrm{Dy}\left(\mathrm{L}^{1}\right)_{3}\right]\left(\mathrm{C}_{57} \mathrm{H}_{66} \mathrm{DyN}_{3} \mathrm{O}_{3}, \mathrm{MW}=1003.62\right): \mathrm{C}, 68.15 \% ; \mathrm{H}$, $6.57 \%$; N, $4.18 \%$. Found: C, $68.21 \% ; \mathrm{H}, 6.67 \%$; N, $4.26 \%$.

Synthesis of $\left[\operatorname{Er}\left(\mathrm{L}^{1}\right)_{3}\right](1 \mathrm{Er})$. 1Er were synthesized using a procedure similar to that for 1Dy with the replacement of $\operatorname{Dy}\left(\mathrm{N}\left(\mathrm{SiMe}_{3}\right)_{2}\right)_{3}$ by $\operatorname{Er}\left(\mathrm{N}\left(\mathrm{SiMe}_{3}\right)_{2}\right)_{3}$. Yield: $\sim 70 \%$. Selected IR $\left(\mathrm{cm}^{-1}\right): 2959(\mathrm{~s})$, $2926(\mathrm{~m}), 1603$ (s), $1583(\mathrm{~s}), 1536(\mathrm{~s}), 1464(\mathrm{~m}), 1444(\mathrm{~s}), 1381(\mathrm{~m}), 1360(\mathrm{w}), 1342(\mathrm{~s}), 1320(\mathrm{~m}), 1254(\mathrm{w})$, $1200(\mathrm{w}), 1167(\mathrm{~m}), 1143(\mathrm{~m}), 1106(\mathrm{w}), 921(\mathrm{~m}), 851(\mathrm{~m}), 792(\mathrm{~m}), 750(\mathrm{~m}), 739(\mathrm{~m}), 594(\mathrm{w})$. Anal. Calcd. for $\left[\operatorname{Er}\left(\mathrm{L}^{1}\right)_{3}\right]\left(\mathrm{C}_{57} \mathrm{H}_{66} \operatorname{ErN}_{3} \mathrm{O}_{3}, \mathrm{MW}=1008.38\right): \mathrm{C}, 67.83 \% ; \mathrm{H}, 6.55 \% ; \mathrm{N}, 4.16 \%$. Found: $\mathrm{C}, 67.72 \%$; H, $6.79 \% ; \mathrm{N}, 4.08 \%$.

Synthesis of $\left[\mathrm{Dy}\left(\mathrm{L}^{2}\right)_{2}\right]$ (2Dy). A solution of $\mathrm{Dy}\left(\mathrm{N}\left(\mathrm{SiMe}_{3}\right)_{2}\right)_{3}(0.5 \mathrm{mmol})$ in pentane was added dropwise to a solution of $\mathrm{H}_{2} \mathrm{~L}^{2}(1 \mathrm{mmol})$ in pentane at $-78^{\circ} \mathrm{C}$. The solution was stirred overnight at room temperature and then filtered. The final filtrate was left unperturbed at room temperature, X-ray quality crystals of 2Dy were obtained after few days. Yield: $\sim 60 \%$. Anal. Calcd. for [Dy $\left.\left(\mathrm{L}^{2}\right)_{2}\right]$ $\left(\mathrm{C}_{68} \mathrm{H}_{109} \mathrm{DyN}_{4} \mathrm{O}_{4}, \mathrm{MW}=1209.09\right): \mathrm{C}, 67.48 \% ; \mathrm{H}, 9.02 \%$; N, 4.63\%. Found: C, 67.52\%; H, 9.09\%; $\mathrm{N}, 4.59 \%$. 


\section{Conclusions}

In summary, we have synthesized and characterized three Ln-based mononuclear complexes, 1Dy, 1Er, and 2Dy, which show distinct magnetic properties. In complexes 1Dy and 1Er, the trigonal-prismatic coordination geometry provides an axial ligand field, which is in favor of the oblate Dy ${ }^{I I I}$ ion rather than the prolate Er ${ }^{\mathrm{III}}$ ion; therefore, 1Dy exhibits the better magnetic properties with $U_{\text {eff }}=31.4 \mathrm{~K}$ under a zero dc field. $1 \mathrm{Er}$ shows field-induced SIM properties with $U_{\text {eff }}=23.96 \mathrm{~K}$ under a 400 Oe dc field. Complex 2Dy with the $O_{\mathrm{h}}$ symmetry only displays the frequency dependence of ac signals without $\chi^{\prime \prime}$ peaks under the zero dc field, indicating the presence of fast QTM relaxation. For six-coordinate dysprosium complexes, the trigonal-prismatic coordination geometry is much more favorable to designing effective SIMs.

Supplementary Materials: The following are available online at www.mdpi.com/2304-6740/6/1/16/s1. Cif and Checkcif files. Table S1: Selected bond distances $[\AA]$ and angles $\left[{ }^{\circ}\right]$ for complexes 1Dy, 1Er, and 2Dy. Table S2: Lanthanide geometry analysis by SHAPE software for 1Dy, 1Er, and 2Dy. Table S3: Best-fit parameters for the Arrhenius plots of 1Dy and 1Er. Figure S1: X-ray structures of complexes 1Dy. The green planes represent the coordination planes with labeled dihedral angle $(\theta)$. Solvents and hydrogen atoms have been omitted for clarity. Figure S2: Packing diagram of 2 viewed along the $c$-axis. Figure S3: X-ray structures of complexes 1Er. The green planes represent the coordination planes with labeled dihedral angle $(\theta)$. Solvents and hydrogen atoms have been omitted for clarity. Figure S4: Packing diagram of 1Er viewed along the $c$-axis. Figure S5: Packing diagram of 2Dy viewed along the $c$-axis. Figure S6: Molar magnetization $(M)$ versus field $(H)$ for complex 1Dy at 1.9, 3.0, and 5.0 K. Figure S7: Molar magnetization $(M)$ versus field $(H)$ for complex 1 Er at 1.9, 3.0, and 5.0 K. Figure S8: Molar magnetization $(M)$ versus field $(H)$ for complex 2Dy at 1.9, 3.0, and 5.0 K. Figure S9: Temperature dependent in phase $\left(\chi^{\prime}\right)$ and out of phase $\left(\chi^{\prime \prime}\right)$ ac susceptibilities for complexes 1Dy at indicated frequencies under a zero dc field. Figure S10: Temperature dependence in phase $\left(\chi^{\prime}\right)$ and out of phase $\left(\chi^{\prime \prime}\right)$ ac susceptibilities for complexes 1Er under zero dc field. Figure S11: The field dependence of the out-of-phase signals of 1Er and 2Dy on applied dc field strength at $1.9 \mathrm{~K}$ and $997 \mathrm{~Hz}$. Figure S12: Temperature dependent in phase $\left(\chi^{\prime}\right)$ and out of phase $\left(\chi^{\prime \prime}\right)$ ac susceptibilities for complexes 1Er under a 400 Oe dc field. Figure S13: Temperature dependent in phase $\left(\chi^{\prime}\right)$ and out of phase $\left(\chi^{\prime \prime}\right)$ ac susceptibilities for complexes 2Dy under a zero dc field.

Acknowledgments: We thank the National Natural Science Foundation of China (Grants 21525103, 21331003, and 21521092) for financial support.

Author Contributions: Jinkui Tang designed and supervised the research. Mei Guo carried out the synthesis and characterization studies. Mei Guo and Jinkui Tang wrote the paper.

Conflicts of Interest: The authors declare no conflict of interest.

\section{References}

1. Gatteschi, D.; Sessoli, R.; Villain, J. Molecular Nanomagnets; Oxford University Press: New York, NY, USA, 2006.

2. Tang, J.; Zhang, P. Lanthanide Single Molecule Magnets; Springer: Berlin/Heidelberg, Germany, 2015.

3. Vincent, R.; Klyatskaya, S.; Ruben, M.; Wernsdorfer, W.; Balestro, F. Electronic read-out of a single nuclear spin using a molecular spin transistor. Nature 2012, 488, 357-360. [CrossRef] [PubMed]

4. Cervetti, C.; Rettori, A.; Pini, M.G.; Cornia, A.; Repolles, A.; Luis, F.; Dressel, M.; Rauschenbach, S.; Kern, K.; Burghard, M.; et al. The classical and quantum dynamics of molecular spins on graphene. Nat. Mater. 2016, 15, 164-168. [CrossRef] [PubMed]

5. Mannini, M.; Pineider, F.; Sainctavit, P.; Danieli, C.; Otero, E.; Sciancalepore, C.; Talarico, A.M.; Arrio, M.-A.; Cornia, A.; Gatteschi, D.; et al. Magnetic memory of a single-molecule quantum magnet wired to a gold surface. Nat. Mater. 2009, 8, 194-197. [CrossRef] [PubMed]

6. Eliseeva, S.V.; Bunzli, J.-C.G. Rare earths: Jewels for functional materials of the future. New J. Chem. 2011, 35, 1165-1176. [CrossRef]

7. Sessoli, R.; Powell, A.K. Strategies towards single molecule magnets based on lanthanide ions. Coord. Chem. Rev. 2009, 253, 2328-2341. [CrossRef]

8. Dunbar, K.R. Editorial for the virtual issue on quantum molecular magnets. Inorg. Chem. 2012, 51, 12055-12058. [CrossRef] [PubMed]

9. Pedersen, K.S.; Bendix, J.; Clerac, R. Single-molecule magnet engineering: Building-block approaches. Chem. Commun. 2014, 50, 4396-4415. [CrossRef] [PubMed] 
10. Sessoli, R.; Gatteschi, D.; Caneschi, A.; Novak, M.A. Magnetic bistability in a metal-ion cluster. Nature 1993, 365, 141-143. [CrossRef]

11. Aubin, S.M.J.; Wemple, M.W.; Adams, D.M.; Tsai, H.-L.; Christou, G.; Hendrickson, D.N. Distorted $\mathrm{Mn}^{\mathrm{IV}} \mathrm{Mn}_{3}{ }_{3}$ cubane complexes as single-molecule magnets. J. Am. Chem. Soc. 1996, 118, 7746-7754. [CrossRef]

12. Guo, F.-S.; Day, B.M.; Chen, Y.-C.; Tong, M.-L.; Mansikkamäki, A.; Layfield, R.A. A dysprosium metallocene single-molecule magnet functioning at the axial limit. Angew. Chem. Int. Ed. 2017, 56, 11445-11449. [CrossRef] [PubMed]

13. Goodwin, C.A.P.; Ortu, F.; Reta, D.; Chilton, N.F.; Mills, D.P. Molecular magnetic hysteresis at 60 kelvin in dysprosocenium. Nature 2017, 548, 439-442. [CrossRef] [PubMed]

14. Rinehart, J.D.; Fang, M.; Evans, W.J.; Long, J.R. Strong exchange and magnetic blocking in $\mathrm{N}_{2}{ }^{3-}$-radical-bridged lanthanide complexes. Nat. Chem. 2011, 3, 538-542. [CrossRef] [PubMed]

15. Rinehart, J.D.; Fang, M.; Evans, W.J.; Long, J.R. A N ${ }^{3-}$ radical-bridged terbium complex exhibiting magnetic hysteresis at 14 K. J. Am. Chem. Soc. 2011, 133, 14236-14239. [CrossRef] [PubMed]

16. Guo, Y.-N.; Xu, G.-F.; Wernsdorfer, W.; Ungur, L.; Guo, Y.; Tang, J.; Zhang, H.-J.; Chibotaru, L.F.; Powell, A.K. Strong axiality and ising exchange interaction suppress zero-field tunneling of magnetization of an asymmetric Dy 2 single-molecule magnet. J. Am. Chem. Soc. 2011, 133, 11948-11951. [CrossRef] [PubMed]

17. Zhang, L.; Zhang, P.; Zhao, L.; Lin, S.-Y.; Xue, S.; Tang, J.; Liu, Z. Two locally chiral dysprosium compounds with salen-type ligands that show slow magnetic relaxation behavior. Eur. J. Inorg. Chem. 2013, 1351-1357. [CrossRef]

18. Gatteschi, D.; Sessoli, R.; Sorace, L. Magnetic bistability in lanthanide-based molecular systems: The role of anisotropy and exchange interactions. In Handbook on the Physics and Chemistry of Rare Earths; Bünzli, J.-C.G., Pecharsky, V.K., Eds.; Elsevier: Amsterdam, The Netherlands, 2016; Volume 50, pp. 91-139.

19. Rinehart, J.D.; Long, J.R. Exploiting single-ion anisotropy in the design of f-element single-molecule magnets. Chem. Sci. 2011, 2, 2078-2085. [CrossRef]

20. Ishikawa, N.; Sugita, M.; Ishikawa, T.; Koshihara, S.-Y.; Kaizu, Y. Lanthanide double-decker complexes functioning as magnets at the single-molecular level. J. Am. Chem. Soc. 2003, 125, 8694-8695. [CrossRef] [PubMed]

21. Wu, J.; Jung, J.; Zhang, P.; Zhang, H.; Tang, J.; Le Guennic, B. Cis-trans isomerism modulates the magnetic relaxation of dysprosium single-molecule magnets. Chem. Sci. 2016, 7, 3632-3639. [CrossRef]

22. Wu, J.; Cador, O.; Li, X.-L.; Zhao, L.; Le Guennic, B.; Tang, J. Axial ligand field in $D_{4 d}$ coordination symmetry: Magnetic relaxation of Dy SMMs perturbed by counteranions. Inorg. Chem. 2017, 56, 11211-11219. [CrossRef] [PubMed]

23. Chen, Y.-C.; Liu, J.-L.; Ungur, L.; Liu, J.; Li, Q.-W.; Wang, L.-F.; Ni, Z.-P.; Chibotaru, L.F.; Chen, X.-M.; Tong, M.-L. Symmetry-supported magnetic blocking at $20 \mathrm{~K}$ in pentagonal bipyramidal Dy(III) single-ion magnets. J. Am. Chem. Soc. 2016, 138, 2829-2837. [CrossRef] [PubMed]

24. Ding, Y.-S.; Chilton, N.F.; Winpenny, R.E.P.; Zheng, Y.-Z. On approaching the limit of molecular magnetic anisotropy: A near-perfect pentagonal bipyramidal dysprosium(III) single-molecule magnet. Angew. Chem. Int. Ed. 2016, 55, 16071-16074. [CrossRef] [PubMed]

25. Gupta, S.K.; Rajeshkumar, T.; Rajaraman, G.; Murugavel, R. An air-stable Dy(III) single-ion magnet with high anisotropy barrier and blocking temperature. Chem. Sci. 2016, 7, 5181-5191. [CrossRef]

26. Zhang, P.; Zhang, L.; Wang, C.; Xue, S.; Lin, S.-Y.; Tang, J. Equatorially coordinated lanthanide single ion magnets. J. Am. Chem. Soc. 2014, 136, 4484-4487. [CrossRef] [PubMed]

27. Zhang, P.; Jung, J.; Zhang, L.; Tang, J.; Le Guennic, B. Elucidating the magnetic anisotropy and relaxation dynamics of low-coordinate lanthanide compounds. Inorg. Chem. 2016, 55, 1905-1911. [CrossRef] [PubMed]

28. Na, B.; Zhang, X.-J.; Shi, W.; Zhang, Y.-Q.; Wang, B.-W.; Gao, C.; Gao, S.; Cheng, P. Six-coordinate lanthanide complexes: Slow relaxation of magnetization in the dysprosium(III) complex. Chem.-A Eur. J. 2014, 20, 15975-15980. [CrossRef] [PubMed]

29. Brown, A.J.; Pinkowicz, D.; Saber, M.R.; Dunbar, K.R. A trigonal-pyramidal erbium(III) single-molecule magnet. Angew. Chem. Int. Ed. 2015, 54, 5864-5868. [CrossRef] [PubMed]

30. Long, J.; Shestakov, B.G.; Liu, D.; Chibotaru, L.F.; Guari, Y.; Cherkasov, A.V.; Fukin, G.K.; Trifonov, A.A.; Larionova, J. An organolanthanide(III) single-molecule magnet with an axial crystal-field: Influence of the raman process over the slow relaxation. Chem. Commun. 2017, 53, 4706-4709. [CrossRef] [PubMed] 
31. Lu, J.; Guo, M.; Tang, J. Recent developments in lanthanide single-molecule magnets. Chem. Asian J. 2017, 12, 2772-2779. [CrossRef] [PubMed]

32. Chilton, N.F.; Langley, S.K.; Moubaraki, B.; Soncini, A.; Batten, S.R.; Murray, K.S. Single molecule magnetism in a family of mononuclear $\beta$-diketonate lanthanide(III) complexes: Rationalization of magnetic anisotropy in complexes of low symmetry. Chem. Sci. 2013, 4, 1719-1730. [CrossRef]

33. Liu, S.-S.; Meng, Y.-S.; Zhang, Y.-Q.; Meng, Z.-S.; Lang, K.; Zhu, Z.-L.; Shang, C.-F.; Wang, B.-W.; Gao, S. A six-coordinate dysprosium single-ion magnet with trigonal-prismatic geometry. Inorg. Chem. 2017, 56, 7320-7323. [CrossRef] [PubMed]

34. Meihaus, K.R.; Rinehart, J.D.; Long, J.R. Dilution-induced slow magnetic relaxation and anomalous hysteresis in trigonal prismatic dysprosium(III) and uranium(III) complexes. Inorg. Chem. 2011, 50, 8484-8489. [CrossRef] [PubMed]

35. Meihaus, K.R.; Minasian, S.G.; Lukens, W.W.; Kozimor, S.A.; Shuh, D.K.; Tyliszczak, T.; Long, J.R. Influence of pyrazolate vs $n$-heterocyclic carbene ligands on the slow magnetic relaxation of homoleptic trischelate lanthanide(III) and uranium(III) complexes. J. Am. Chem. Soc. 2014, 136, 6056-6068. [CrossRef] [PubMed]

36. Liu, J.-L.; Yuan, K.; Leng, J.-D.; Ungur, L.; Wernsdorfer, W.; Guo, F.-S.; Chibotaru, L.F.; Tong, M.-L. A six-coordinate ytterbium complex exhibiting easy-plane anisotropy and field-induced single-ion magnet behavior. Inorg. Chem. 2012, 51, 8538-8544. [CrossRef] [PubMed]

37. Layfield, R.A.; Murugesu, M. Lanthanides and Actinides in Molecular Magnetism; John Wiley \& Sons: Weinheim, Germany, 2015.

38. Baldoví, J.J.; Cardona-Serra, S.; Clemente-Juan, J.M.; Coronado, E.; Gaita-Ariño, A.; Palii, A. Rational design of single-ion magnets and spin qubits based on mononuclear lanthanoid complexes. Inorg. Chem. 2012, 51, 12565-12574. [CrossRef] [PubMed]

39. Le Roy, J.J.; Korobkov, I.; Murugesu, M. A sandwich complex with axial symmetry for harnessing the anisotropy in a prolate erbium(III) ion. Chem. Commun. 2014, 50, 1602-1604. [CrossRef] [PubMed]

40. Konig, S.N.; Chilton, N.F.; Maichle-Mossmer, C.; Pineda, E.M.; Pugh, T.; Anwander, R.; Layfield, R.A. Fast magnetic relaxation in an octahedral dysprosium tetramethyl-aluminate complex. Dalton Trans. 2014, 43, 3035-3038. [CrossRef] [PubMed]

41. Pinsky, M.; Avnir, D. Continuous symmetry measures. 5. The classical polyhedra. Inorg. Chem. 1998, 37, 5575-5582. [CrossRef] [PubMed]

42. Alvarez, S.; Avnir, D.; Llunell, M.; Pinsky, M. Continuous symmetry maps and shape classification. The case of six-coordinated metal compounds. New J. Chem. 2002, 26, 996-1009. [CrossRef]

43. Ruiz, J.; Mota, A.J.; Rodriguez-Dieguez, A.; Oyarzabal, I.; Seco, J.M.; Colacio, E. Rational design of ferromagnetic coupled diphenoxocarboxylate triply bridged dinuclear nickel(II) complexes: Orbital countercomplementarity of the bridging ligands. Dalton Trans. 2012, 41, 14265-14273. [CrossRef] [PubMed]

44. Guo, M.; Xu, Y.; Wu, J.; Zhao, L.; Tang, J. Geometry and magnetic interaction modulations in dinuclear Dy2 single-molecule magnets. Dalton Trans. 2017, 46, 8252-8258. [CrossRef] [PubMed]

45. Cole, K.S.; Cole, R.H. Dispersion and absorption in dielectrics I. Alternating current characteristics. J. Chem. Phys. 1941, 9, 341-351. [CrossRef]

46. Ungur, L.; Chibotaru, L.F. Strategies toward high-temperature lanthanide-based single-molecule magnets. Inorg. Chem. 2016, 55, 10043-10056. [CrossRef] [PubMed]

47. Chilton, N.F.; Collison, D.; McInnes, E.J.L.; Winpenny, R.E.P.; Soncini, A. An electrostatic model for the determination of magnetic anisotropy in dysprosium complexes. Nat. Commun. 2013, 4, 2551. [CrossRef] [PubMed]

48. Bradley, D.C.; Ghotra, J.S.; Hart, F.A. Low co-ordination numbers in lanthanide and actinide compounds. Part I. The preparation and characterization of tris\{bis(trimethylsilyl)-amido\}lanthanides. J. Chem. Soc. Dalton Trans. 1973, 1021-1023. [CrossRef]

49. Sun, Y.; Wu, G.; Cen, D.; Chen, Y.; Wang, L. Synthesis and catalytic activity of heterogeneous rare-earth metal catalysts coordinated with multitopic schiff-base ligands. Dalton Trans. 2012, 41, 9682-9688. [CrossRef] [PubMed]

50. Tshuva, E.Y.; Goldberg, I.; Kol, M.; Goldschmidt, Z. Zirconium complexes of amine-bis(phenolate) ligands as catalysts for 1-hexene polymerization: Peripheral structural parameters strongly affect reactivity. Organometallics 2001, 20, 3017-3028. [CrossRef] 
51. Kerton, F.M.; Holloway, S.; Power, A.; Soper, R.G.; Sheridan, K.; Lynam, J.M.; Whitwood, A.C.; Willans, C.E. Accelerated syntheses of amine-bis(phenol) ligands in polyethylene glycol or "on water" under microwave irradiation. Can. J. Chem. 2008, 86, 435-443. [CrossRef]

52. Sheldrick, G.M. SHELXS-97 Program for Crystal Structure Solution; University of Göttingen: Göttingen, Germany, 1997.

53. Sheldrick, G. A short history of SHELX. Acta Crystallogr. Sect. A 2008, 64, 112-122. [CrossRef] [PubMed]

54. Sheldrick, G. Crystal structure refinement with SHELXL. Acta Crystallogr. Sect. C 2015, 71, 3-8. [CrossRef] [PubMed]

55. Bain, G.A.; Berry, J.F. Diamagnetic corrections and pascal's constants. J. Chem. Educ. 2008, 85, 532. [CrossRef] C 2018 by the authors. Licensee MDPI, Basel, Switzerland. This article is an open access article distributed under the terms and conditions of the Creative Commons Attribution (CC BY) license (http://creativecommons.org/licenses/by/4.0/). 